\title{
Inter-arm blood pressure difference in healthy young adults: a cross-sectional study
}

\author{
Dilli Bahadur Pun', Sonam Chaudhary', Prashanna Shrestha' , Bobby Thapa ${ }^{2}$, Nirjala Laxmi Madhikarmi
}

\section{Author(s) info:}

${ }^{1}$ Department of Physiology, Kantipur Dental College, Kathmandu, Nepal

${ }^{2}$ Nepalgunj Nursing Campus, Institute of Medicine, Banke, Nepal

${ }^{3}$ Department of Biochemistry, Kantipur Dental College,

Kathmandu, Nepal

\section{Correspondence:}

Dr. Dilli Bahadur Pun, BDS, MD

Department of Physiology,

Kantipur Dental College,

Kathmandu, Nepal

Email:

dillipun_173@gmail.com

\begin{abstract}
Introduction: Inter-arm difference (IAD) in blood pressure is the difference in the systolic and the diastolic blood pressure between arms of an individual. Studies regarding IAD among elderly, pregnant women, patients with cardiovascular disease and diabetes have been conducted but there are very limited studies carried out among young healthy adults. Thus, this study aimed to investigate the inter-arm blood pressure difference and its association with age, sex, BMI and family history of hypertension among Nepalese healthy young adults.
\end{abstract}

Materials and methods: A cross-sectional study was carried out among 230 students of Kantipur Dental College, Kathmandu, Nepal. Blood pressure was measured using a mercurial sphygmomanometer. Statistical analysis was done using paired t test, chi-square and Pearson's correlation test using SPSS 16.

Results: The absolute mean IAD for SBP was $5.03 \pm 3.88 \mathrm{~mm} \mathrm{Hg}$ and for DBP was $3.84 \pm 3.77 \mathrm{~mm} \mathrm{Hg}$. There is significant inter-arm difference for SBP $(\mathrm{t}=4.882, \mathrm{p}<0.001)$ but not for DBP. Inter-arm SBP difference was significantly associated with family history of hypertension $\left(\chi^{2}=6.41, \mathrm{p}=0.01\right)$ and positive but weakly correlated with age $(r=+0.135, p=0.04)$. There is no significant association of inter-arm SBP difference with sex and BMI. Meanwhile, there is no statistically significant association of sex, family history of hypertension, age and BMI with inter-arm DBP.

Conclusions: There is a significant inter-arm systolic blood pressure difference among the healthy young Nepalese adults and it is associated with the positive family history of hypertension and age.

Keywords: blood pressure, inter-arm difference, young adults
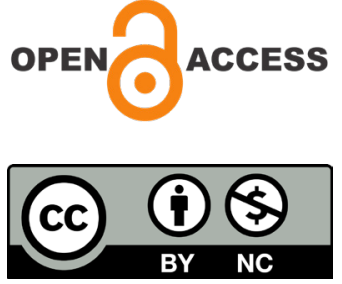

○ JPSN 


\section{INTRODUCTION}

Hypertension (HTN) is a global health challenge and a major cause of cardiovascular disease and premature death throughout the world. [1] Globally, about 1.13 billion people are affected by hypertension, of which nearly two-third belongs to low- and middle-income countries.[2] In Nepal, its prevalence is $28.4 \%$ in urban, $25.5 \%$ in suburban and $24.4 \%$ in rural areas.[3]

Blood pressure (BP) measurement is a confirmatory assessment performed to diagnose hypertension. In clinical practice, BP measurement is often a routinely performed, and regular monitoring of BP may aid in preventing hypertension. However, studies have revealed that BP recording values often differ between arms, and can cause errors in BP interpretation and management.[4,5] Thus, most of the guidelines recommend to measure BP in both arms at the first assessment and arm with greater value for subsequent measurements.6,7 Nevertheless, this practice has not been followed by the majority of the clinicians. $[6,8]$

Inter-arm difference (IAD), which is the difference in BP between right and left arm has been found to be associated with hypertension, [4] diabetes,[9] chronic renal disease[10] or peripheral vascular disease.[11] A study reported that the IAD $\geq 10$ $\mathrm{mm} \mathrm{Hg}$ and positive family history of hypertension and diabetes has a prognostic value in predicting cardiovascular events.[12] It is also found that IAD assessment has the potential to act as a simple non-invasive test, identifying those prone to cardiovascular and peripheral vascular events. [13] Until now, many IAD studies have been focused among older individuals,[14] person with diabetes,[9] hypertension[4] and among pregnant women.[15] Nonetheless, there are very limited studies done among the healthy young adults. Also, we are unaware of the presence of any other factors associated with IAD among the young adults. So, with the objective of identifying the IAD and its association with age, sex, body mass index (BMI) and family history of hypertension, a study was conducted among the Nepalese young adults.

\section{MATERIALS AND METHODS}

This cross-sectional observational study was conducted from September 2019 to February 2020 among 230 students in the Department of Physiology of Kantipur Dental College Teaching
Hospital (KDCH) Kathmandu, Nepal. A nonprobability purposive sampling technique was used. Students with a history of hypertension, cardiovascular disease, kidney disease, who were on medication and who were not willing to participate were excluded from this study. The ethical clearance was taken from the Institutional Review Committee (IRC) of Kantipur Dental College before conducting the study. Informed written consent was taken from the participants prior to data collection.

Weight measurement: Weight was taken using standard digital weighing scale. The scale was kept on a flat surface and the participant was requested to stand in the center of the scale with bare foot without any support. The students were asked to face front while standing on the weighing scale.

Height measurement: The height was taken using a non elastic measuring tape, bare foot upon firm even surfaced floor.

Blood pressure measurement: Blood pressure was measured with the standard mercurial sphygmomanometer. Participants were asked to sit comfortably and rest 5 minutes with legs uncrossed. The sphygmomanometer was kept at the level of heart and hands were supported during BP measurement. It was made sure that the size of cuffs was correct for the subject's arm circumference. The pressure at which Korotkoff's sound first heard (Phase I) was taken as systolic BP, and the pressure at which these sounds disappeared (Phase V) was taken as diastolic BP. BP was measured twice in each arm (with at least 3 minutes rest between each reading) and the values were averaged. Inter-arm blood pressure was calculated as the difference in the average values of systolic and diastolic BP between the right and left arm. $[16,17]$

Data management and analysis: All the collected data was compiled, coded and entered in Microsoft excel and analyzed using Statistical package for social sciences version 16 (SPSS 16.0). Descriptive statistics was used to compute mean and standard deviation. Inferential statistics such as paired t-test was done to identify if there is any significant difference between inter-arm systolic and diastolic BP. Chi-square test was done to explore the association between systolic and diastolic interarm BP difference with sex and family history of hypertension whereas, Pearson's correlation test was done to determine the correlation between the 
age and BMI with systolic and diastolic inter-arm BP difference.

\section{RESULTS}

Total 230 student's aged between 17-27 years (mean $20.23 \pm 2.3$ years) participated in the study. Mean height and mean weight of the participants was $159.45 \pm 0.77 \mathrm{~cm}$ and $55.66 \pm 9.76 \mathrm{~kg}$ respectively. Mean BMI of the participants was $21.81 \pm 2.92 \mathrm{~kg} /$ $\mathrm{m}^{2}$. Most participants were females, had normal body mass index and had no family history of hypertension (Table 1).

The mean right arm systolic blood pressure (SBP) and diastolic blood pressure (DBP) were $109.90 \pm 11.49 \mathrm{~mm} \mathrm{Hg}$ and $71.72 \pm 9.36 \mathrm{~mm} \mathrm{Hg}$ respectively. Similarly, the mean left arm SBP and
Table 1: General characteristics and family history of hypertension (HTN) of the participants $(n=230)$

Table 2: Comparison of inter-arm differences of blood pressures in relation to sex and family history of hypertension

\begin{tabular}{|c|c|c|c|c|c|}
\hline \multirow{2}{*}{\multicolumn{2}{|c|}{ Variables and Categories }} & \multicolumn{2}{|c|}{ SBP difference } & \multicolumn{2}{|c|}{ DBP difference } \\
\hline & & $<10 \mathrm{mmHg}$ & $\geq 10 \mathrm{mmHg}$ & $<10 \mathrm{mmHg}$ & $\geq 10 \mathrm{mmHg}$ \\
\hline \multirow{3}{*}{ Total } & Frequency & 169 & 61 & 189 & 41 \\
\hline & Percentage & 73.48 & 26.52 & 82.17 & 17.83 \\
\hline & Mean difference & \multicolumn{2}{|c|}{$5.03 \pm 3.88$} & \multicolumn{2}{|c|}{$3.84 \pm 3.77$} \\
\hline \multirow{3}{*}{ Sex } & Male & 53 & 13 & 53 & 13 \\
\hline & Female & 116 & 48 & 136 & 28 \\
\hline & $P$ value $\left(\chi^{2}\right)$ & \multicolumn{2}{|c|}{0.12} & \multicolumn{2}{|c|}{0.64} \\
\hline \multirow{3}{*}{$\begin{array}{l}\text { Family history of } \\
\text { hypertension }\end{array}$} & Present & 60 & 11 & 63 & 8 \\
\hline & Absent & 109 & 50 & 126 & 33 \\
\hline & $P$ value $\left(\chi^{2}\right)$ & \multicolumn{2}{|c|}{0.01} & \multicolumn{2}{|c|}{0.08} \\
\hline
\end{tabular}

Table 3: Correlation (Pearson) of age and body mass index and blood pressure interarm differences

\begin{tabular}{|l|c|c|c|c|}
\hline \multirow{2}{*}{ Variables } & \multicolumn{2}{|c|}{ SBP } & \multicolumn{2}{c|}{ DBP } \\
\cline { 2 - 5 } & Correlation coefficient & P value & Correlation coefficient & P value \\
\hline Age & +0.135 & 0.04 & -0.017 & 0.79 \\
\hline BMI & +0.31 & 0.65 & -0.085 & 0.20 \\
\hline
\end{tabular}


DBP were $107.95 \pm 11.40 \mathrm{~mm} \mathrm{Hg}$ and $71.27 \pm 9.15$ $\mathrm{mm} \mathrm{Hg}$ respectively. There is significant IAD for SBP $(\mathrm{t}=4.882, \mathrm{p}<0.001)$ but not for DBP $(\mathrm{t}=$ $5.369, \mathrm{p}=0.20)$. The distribution of inter-arm BP differences is shown in Table 2. The absolute mean IAD for SBP was $5.03 \pm 3.88 \mathrm{~mm}$ of $\mathrm{Hg}$ and for DBP was $3.84 \pm 3.77 \mathrm{~mm} \mathrm{Hg}$. The proportion for IAD $\geq 10$ $\mathrm{mm} \mathrm{Hg}$ for SBP and DBP were found to be $26.5 \%$ and $17.8 \%$ respectively.

Inter-arm SBP difference was significantly associated with family history of hypertension $\left(\chi^{2}\right.$ $=6.41 . \mathrm{p}=0.01$ ) (Table 2 ) and positive but weakly correlated with age $(\mathrm{r}=+0.135, \mathrm{p}=0.04)$ (Table 3). However, there is no significant association with sex and no significant correlation with BMI. Meanwhile, there is no any statistically significant association and correlation of sex, family history of hypertension, age and BMI with inter-arm difference in DBP among the participants.

\section{DISCUSSION}

The present study investigated the distributions of inter-arm BP differences in healthy young adults and identified their associated factors. It confirms the presence of significant inter-arm difference in systolic blood pressure in young healthy individuals but no difference in the diastolic blood pressure. Our results also revealed that the right arm BP was higher than the left arm BP, which is consistent with the results of previous studies. $[12,16,18,19]$ It may be because the muscles in the dominant arm are more developed than the nondominant arm and hence are less compressed by the BP cuffs. Also, various reasons are suggested of which one suggest slight anatomical variances are present in angulations and branching of the aorta as well as hemodynamic profiles which might have reproduced the result.[19,20]

Inter-arm differences $\geq 10 \mathrm{mmHg}$ in $\mathrm{SBP}$ and DBP were found to be $26.5 \%$ and $17.8 \%$ of participants respectively, which is nearer to some previous studies, $[13,21,22]$ whereas, other studies have shown prevalence values lower than this study.[12,16,19,23] This might be due to differences in study populations and methods used to measure BP. Our study used a sequential method for measurement of BP which might have resulted in a higher prevalence rate. Studies performed using simultaneous automated repeated measurement techniques have reported lower prevalence of an inter-arm difference in blood pressure[22,23] than those using sequential measurements. [24,25]

In this study, systolic inter-arm pressure difference was significantly associated with a positive family history of hypertension. It shows that people with a family history of hypertension are more prone to inter-arm BP differences. A previous study observed subjects with family history of hypertension had systolic inter-arm difference of more than $10 \mathrm{~mm} \mathrm{Hg},[18]$ which also correlates with the finding of Igarashi et al who reported IAD blood pressure is often found in patients with suspected coronary and peripheral artery disease.[20] Thus inter-arm pressure difference may be regarded as a simple marker for coronary and peripheral artery diseases. Whereas the study by Lane et al did not find any relation between inter-arm difference and the presence of hypertension, diabetes mellitus, or previous cardiovascular disease.[26]

Our study also revealed a statistically significant weak positive correlation between SBP inter-arm difference and age which is similar to the finding of a previous study.[27] In contrast, a study had found no association between inter-arm BP difference and age.[23] It was also reported that although age does not affect mean inter-arm BP difference, clinically important inter-arm BP difference does exist in both young and elderly subjects, which highlights the need for BP measurements in both arms of all patients at initial assessment.[23]

In the present study, no significant correlation was noted between inter-arm blood pressure difference and BMI. A previous study also observed similar finding 18. However, in a another previous study, a large absolute inter-arm difference in SBP was reported to be independently associated with BMI. [32] Study done by Kumari et al revealed that the inter-arm systolic pressure difference is not significant in the younger age group of 18 to 25 years, whose $\mathrm{BMI}$ is less than $25 \mathrm{~kg} / \mathrm{m}^{2}$. But positive correlation was seen in the individuals between ages of 40-50 years with overweight.[28]

In our study, no association was found between IAD in BP and sex. Many previous studies have shown that mean IAD was unrelated to sex.[20,29] The possible reason for the insignificance might be due to the unequal proportion of different gender in the study population, where the female have over represented and male have underrepresented the whole population. 
Limitations : The study site included a small population in a dental college which may not represent the whole population. The study used a sequential method for measurement of BP. For accurate assessment blood pressure should be measured simultaneously in both arms.

\section{CONCLUSION}

There is a significant inter-arm systolic blood pressure difference among the healthy young Nepalese adults and it is associated with the positive family history of hypertension and age. Presence of significant inter-arm systolic blood pressure differences suggest that the blood pressure should be taken in both arms at the initial consultation even in healthy young adults.

\section{CONFLICT OF INTEREST}

None

\section{REFERENCES}

1. Mills KT, Stefanescu A, He J. The global epidemiology of hypertension. Nat Rev Nephrol 2020; 16(4): 223-37.

2. Hypertension, https://www.who.int/health-topics/ hypertension/(accessed 12 July 2020)

3. Huang Y, Guo P, Karmacharya BM, Seeruttun SR, Xu DR, Hao Y. Prevalence of hypertension and prehypertension in Nepal: a systematic review and meta-analysis. Glob Health Res Policy 2019; 4(1): 11.

4. Clark CE, Campbell JL, Evans PH, Millward A. Prevalence and clinical implications of the inter-arm blood pressure difference: a systematic review. J Hum Hypertens 2006; 20: 923-31.

5. Kulkarni PK, Shekhar S, Reddy BN, Nirmala BC. Blood pressure measurement: one arm or both arm? Indian J Med Sci 2011; 65(9): 406-10.

6. Heneghan C, Perera R, Mant D, Glasziou P. Hypertension guideline recommendations in general practice: awareness, agreement, adoption, and adherence. Br J Gen Pract 2007; 57(545): 948-52.

7. Smith L. New AHA recommendations for blood pressure measurement: American Heart Association Practice Guidelines. Am Fam Physician. 2005;72:1391-98.

8. Verberk WJ, Kessel AG, Thien T. BP measurement method and inter-arm difference: a meta-analysis. Am J Hypertens 2011; 24(11): 1201-8.

9. Clark CE, Greaves C, Evans PH, Dickens A, Campbell JL. The inter-arm blood pressure difference in Type 2 diabetes: a barrier to effective management? Br J Gen Pract 2009;
59: 428-32.

10. Agarwal R, Bunaye Z, Bekele DM. Prognostic significance of Between-Arm Blood Pressure Differences. Hypertension 2008; 51(3): 657-62.

11. Aboyans V, Criqui MH, McDermott MM, et al. The Vital prognosis of subclavian stenosis. J Am Coll Cardio 2007; 49(14): 1540-5.

12. Verma MK, Tripathi S, John NA, John JE. Inter-arm blood pressure difference, pulse pressure and mean arterial pressure as predictors of cardiovascular disease risk in young adults. Int J Clin Exp Physiol 2018; 5(1): 44-7.

13. Clark CE, Taylor RS, Shore AC, Campbell JL. The difference in blood pressure readings between arms and survival: primary care cohort study. BMJ 2012; 344: e1327

14. Sharma B, Ramawat P. Prevalence of inter-arm blood pressure difference among clinical out-patients. Int $J$ Health Sci 2016; 10(2): 229-37.

15. Poon LC, Kametas N, Strobl I, Pachoumi C, Nicolaides $\mathrm{KH}$. Inter-arm blood pressure differences in pregnant women. BJOG 2008; 115(9): 1122-30.

16. Kurian S, Manjula VD, Joseph RP. Prevalence of raised inter-arm BP difference in young healthy adults- a cross sectional study. NJMR 2016; 6: 5-8.

17. Pyakurel P, Yadav DK, Thapa J, et al. Prevalence and associated risk factor of hypertension among individuals of age 18-59 years in South-eastern Nepal: A cross sectional study. Nepalese Heart Journal 2019; 16(1): 19-26.

18. Seethalakshmi K, Bahuleyan B. Inter arm blood pressure difference: An indicator of cardiovascular risk. Int J Res Med Sci 2015; 3(12): 3782-5.

19. Song BM, Kim HC, Shim JS, Lee MH, Choi DP. Interarm difference in brachial blood pressure in the general population of Koreans. Korean Circ J 2016; 46: 374-83.

20. Igarashi Y, Chikamori T, Tomiyama H, Usui Y, Hida S, Tanaka H, Nagao T, Yamashina A. Clinical significance of inter-arm pressure difference and ankle-brachial pressure index in patients with suspected coronary artery disease. J Cardiol 2007; 50(5): 281

21. Verma N, Raju S, Kumar P, Kumai R, Bhardwaj K. Inter arm systolic blood pressure difference is associated with a high prevalence of cardiovascular diseases. Int $J$ Res Med Sci 2016; 4: 1177-80.

22. Harrison $E G$, Roth GM, Hines EA. Bilateral indirect and direct arterial pressures. Circulation 1960; 22: 419-36.

23. Fotherby MD, Panayiotou B, Potter JF. Age-related differences in simultaneous inter-arm blood pressure measurements. Postgrad Med J 1993; 69(809): 194-6.

24. Cassidy P, Jones K. A study of inter-arm blood pressure differences in primary care. J Hum Hypertens 2001; 15(8): 519-22.

25. Clark CE, Powell RJ. The differential blood pressure sign in general practice: prevalence and prognostic value. Fam 
Pract 2002; 19(5): 439-41.

26. Lane $D$, Beevers $M$, Barnes $N$, et al. Inter-arm differences in blood pressure: when are they clinically significant? J Hypertens 2002; 20(6): 1089-95.

27. Kumari NS, Venkateswarulu V, Sundar RM, Bandela SM, Srinivas C. Association of body mass index with inter-arm blood pressure difference: a comparative and cross sectional study. J Evol Med Dent Sci 2015; 24(103): 16850-2.
28. Kimura A, Hashimoto J, Watabe D, Takahashi $\mathrm{H}$, et al. Patient characteristics and factors associated with interarm difference of blood pressure measurements in a general population in Ohasama, Japan. J Hypertens 2004; 22(12): 2277-83.

29. Pesola GR, Pesola HR, Lin M, et al. The normal difference in bilateral indirect blood pressure recordings in hypertensive individuals. Acad Emerg Med 2002; 9(4): 342-5. 